\title{
Overseas Medical Referral: the health system challenges for Pacific Island Countries
}

\author{
Andrea Boudville ${ }^{1}$, Wayne Irava ${ }^{2}$, Silina Motofaga ${ }^{3}$, Katherine Gilbert ${ }^{1}$, \\ Peter Leslie Annear ${ }^{1}$ \\ Nossal Institute for Global Health, The University of Melbourne, 333 Exhibition St Melbourne \\ 3000 Australia, andrea.boudville@unimelb.edu.au, +61 $477160100 .{ }^{1}$ \\ World Bank (formerly with World Health Organization Western Pacific Regional Office-Pacific \\ Division of Technical Support 2018-2019), World Bank Office Honiara Solomon Islands, \\ waynej.irava@gmail.com,+6777418559.2 \\ SPC Pacific Community (formerly with World Health Organization Western Pacific Regional \\ Office-Pacific Division of Technical Support 2018-2019), SPC Private Mail Bag Suva Fiji, \\ silinam@spc.int, +679 337 0733.3 \\ Corresponding author: Nossal Institute for Global Health, The University of Melbourne, 333 \\ Exhibition St Melbourne 3000 Australia, pannear@unimelb.edu.au, +61 410561189.
}

\begin{abstract}
The delivery of specialised clinical services in the small Island nations of the Pacific region is an increasing challenge in the context of a rising burden of non-communicable diseases. Resources are limited and caseloads too low to support local specialists. This article focuses on the common practice of Overseas Medical Referral (OMR), which is an increasing challenge in the region. We collected interview and secondary data across 16 Pacific Island Countries. We found that OMR policies are often weak or incomplete, systems inadequate and reforms needed. Integrating OMR fully into national health referral systems and national strategic planning and prioritisation processes is needed. There is an additional need for collection of routine data on OMR service providers in the recipient countries and the outcomes of clinical care. With these reforms, a move towards increased regional cooperation and some form of strategic purchasing is possible.
\end{abstract}

\section{Keywords}

OMR, referral, specialist care, purchasing

The authors are grateful for the support and collaboration of the Western Pacific Regional Office of the World Health Organization, particularly Prof. Vivian Lin, and the Pacific Community (SPC). Funding for this research was provided by the Asia Pacific Observatory on Health Systems and Policy. We declare no conflict of interest. 


\section{Introduction}

Health policy makers in Pacific Island Countries (PIC) are facing the need to expand the provision of specialised clinical services (SCS) to meet a perceived increase in population demand. Much of the likely growth in demand is related to the rising burden of non-communicable diseases (NCDs) (Hawley \& McGarvey, 2015; Hoy, Roth, Viney, Souares \& Lopez, 2015; Mannava, Abdullah, James, Dodd \& Annear, 2010). The high burden of NCDs together with severe financial- and human-resource constraints make access to SCS a particular concern for the small-island states of the Pacific region (World Health Organization [WHO], 2017; World Bank [WB], 2014).

With small and widely dispersed populations and few trained medical specialists (local or international) (Biscoe, Fakakovikartay, Condon \& Monteiro, 2015; Yamamoto et al., 2010), PIC cannot achieve economies of scale for most SCS or provide the caseload needed to build clinical capacity (Suzana, Walls, Smith \& Hanefeld, 2018; Plowman, 2015; Irava, Mahalakanda \& Prasad, 2014; Masterton, Moss, Korin \& Watters, 2014; Natuzzi et al., 2011; Negin, 2011; Kushner et al., 2010; Theile \& Bennett, 1998).

\section{Specialised Clinical Services and Overseas Medical Referrals}

SCS are typically delivered in three ways in most PIC:

1. By local medical specialists working principally within the public health system, typically at tertiary hospital level (where facilities and resources permit);

2. By visiting specialist medical teams (VSMT) or medical doctors from overseas, largely volunteers, donor-funded or self-funded by overseas charitable organizations (and often dependent on the availability of visiting specialists rather than patient need);

3. By sending patients overseas for treatment, a process known as Overseas Medical Referral (Plowman, 2015; Blick and Smith, 2015; Irava et al, 2014).

This article focuses on the third of these options, Overseas Medical Referral (OMR). Based on an understanding that OMR is unavoidable in the Pacific context, the purpose of this article is to analyse the healthsystem issues involved in meeting the challenge of providing more efficient and more equitable access to OMR services.

This study investigated the policy and process that determines the current extent, implementation, and outcomes of OMR service delivery. In this article we address three key questions:

1. What are the current levels and direction of OMR service provision across PIC?

2. Are OMR policies complete and current, and how do systems function to deliver OMR services in each PIC?

3. What are the health-system issues related to improving access to PIC OMR programmes? 
Gaps in the published OMR literature

The existing published literature on OMR in the Pacific region is limited, and we have canvassed every available source. In various PIC, OMR is at times treated in practice as an activity that lies outside the normal functioning of the national health system, leading to inequities in access to OMR (Plowman, 2015). While each national OMR committee assesses patient access, potential prognosis and value-for-money decisions, the information they have is limited and decisions (sometimes made on an individual basis) may be inconsistent.

Patient access to OMR schemes is at times subject to political influence, which affects access and equity in outcomes (Blick \& Smith 2015; Irava et al., 2014; Irava, 2011). This challenges the aims and ambitions of Pacific Health Ministers expressed in the 2015 Yanuca Island Declaration (WHO, Ministry of Health and Medical Services [MOH\&MS], the Pacific Community [SPC], 2015) and key development partners to achieve universal health coverage (WHO \& World Bank, 2017).

Analysis of the constraints facing OMR from a health systems perspective has been limited and focussed on a small number of countries. Budget constraints, inadequate data and lack of transparency related to referral, coordination and financing have been described as the key challenges (WHO, 2019; Suzana et al., 2018; Plowman, 2015; Theile \& Bennett, 1998). In some PIC, the costs of providing OMR are a significant part of health expenditures. For example, OMR consumed $44 \%$ of the Tuvalu health budget during 2003-13 (Kushner et al., 2010). There is evidence that funding for SCS is 'crowding-out' funding for other areas such as primary and preventative healthcare services (Irava et al., 2014).

Little is known about the quality of care offered by OMR service providers, about patient outcomes, or about value-for-money in service provision. One study of OMR cardiac treatment found, for example, that patient costs in Australia and New Zealand were twice those charged in India (Irava, 2011); another evaluation found no clear evidence that treating OMR patients in India represented better value for money compared to New Zealand (Blick \& Smith, 2015).

Need for policy analysis

In November 2017, a meeting of Pacific health leaders attending the $68^{\text {th }}$ Session of the Regional Committee for the Western Pacific, Brisbane, Australia, raised the need to fully map specialised clinical services to improve access to and the quality of care and explore options for cost saving.

The research on which this article is based was part of a larger study responding to this request and carried out as a collaboration between the WHO Western Pacific Regional Office, the WHO Pacific Office, the SPC, the Asia Pacific Observatory on Health Systems and Policies, and the Nossal Institute for Global Health at the University of Melbourne. The results of the wider mapping of SCS by WHO is available online (Nossal Institute, SPC \& WHO, 2019). A more detailed published report and policy brief on the issue of OMR, based on this research, is available through 
the Asia Pacific Observatory (Boudville, Irava, Motofaga, Gilbert \& Annear, 2020).

\section{Methods}

We analysed the OMR policy challenges faced by PIC governments and donor partners (bilateral and charitable) using comprehensive information from official reports, routine data, and key informants. We surveyed OMR schemes based on government administration and financing (not including private arrangements).

Geographic scope

Data were collected from 16 PIC (refer to Table 1 below) ${ }^{1}$ building on the 2014 study by Irava and colleagues in four PIC (Irava, Mahalakanda \& Prasad, 2014). Seventeen PIC were invited to participate; three did not complete our questionnaire (Nauru declined, New Caledonia and Wallis and Futuna did not respond). For Nauru and New Caledonia, we analysed policy documents and other secondary data (including annual $\mathrm{MOH}$ and budget reports). Papua New Guinea as well as American Samoa and Guam (both US affiliates) were excluded due to logistics and limitations on the cost of and time available for data collection. ${ }^{2}$ Additional data were collected from key informants in Australia and New Zealand.

\section{Literature and documentation}

To prepare for wider data collection we made a comprehensive review of all available literature from peer-reviewed journals and from the grey literature, including PIC government and international donor reports and documentation internal to WHO and the SPC. The aim of the literature review was to identify practices and policy settings related to OMR.

The purpose of the review was to analyse current policies (the degree to which they were up-to-date, comprehensive and available to the public) and current practices (patient selection, benefit provision and choice of providers). Documents used in the analysis included policy documents, annual reports, National Health Accounts (where available) and relevant information from the WHO Global Observatory database.

\section{Routine data}

We collected all available routine data on the delivery of OMR services for each PIC (that is, where routine data were collected by the $\mathrm{MOH}$ ) such as patient numbers, financing and service provision, including both official government reports and international agencies (such as WHO, the SPC).

\section{Questionnaire}

The literature and document reviews provided the foundation for developing a standard questionnaire as a framework for collecting consistent information (needed to fill gaps in the available literature,

\footnotetext{
${ }^{1}$ For 14 countries, analysis was based on information collected by questionnaire and a document review. For 2 countries, data was based on a document review only.

2 The Territory of the Wallis and Futuna Islands (a French island collectivity) and The Northern Mariana Islands (an insular area and commonwealth of the USA) were not included in the study.
} 
documentation, and routine data) across all participating PIC. The questionnaire was prepared in collaboration with the WHO Pacific Office and the office of the SPC. This was not a qualitative survey but rather a guideline for in-country key informants to provide needed information on policies and administrative processes. The categories covered in the questionnaire were OMR policies and laws, financing of OMR, eligible medical conditions, selection of providers, and the selection and management of patients.

\section{Respondents}

Information gathering was carried out by participating researchers from the Pacific offices of WHO and the SPC in-person, by telecommunication or in-writing. Key informants in each PIC were asked to provide information by completing as far as possible the prepared questionnaire (Table 1 summarises the completion of the questionnaire and document collection for each PIC).

The selection of key informants began by seeking permission from the Permanent Secretary of the $\mathrm{MOH}$ in each country for the researchers to contact senior $\mathrm{MOH}$ officials who had oversight of the OMR scheme (which varied between countries). These key informants variously included the Permanent Secretary, Directors of Clinical or Medical Services and OMR Coordinators (or personnel performing similar or equivalent roles where these roles did not exist). Key informants from donor and other relevant organizations also provided information.

Respondents were provided with a plain language statement and asked to complete the questionnaire either during interview or in writing. Potential respondents were invited to participate; respondents volunteered (or self-selected) as a key informant to be interviewed or to complete the survey in writing. Twenty-three questionnaires were completed in three rounds on 31 August, 15 October and 30 November in 2018.

\section{Ethics approval}

Ethics approval was provided by the University of Melbourne Health Ethics Advisory Group and confirmed by the Faculty of Medicine, Dentistry and Health Sciences Human Ethics Subcommittee on 23 October 2018 under the project number 1851408.1 for data collection in the period 23 October to 31 December 2018.

\section{Validation of results}

The researchers conducted a thematic analysis of all collected data and information, based on the categories in the questionnaire. To validate the results, presentations of preliminary findings from this study were made by members of the research team to Pacific health leaders at: (i) the February 26-27, 2019, WHO Meeting on Sub-Regional Collaboration for Specialized Health-care Services (WHO, 2019); (ii) the April 2-3, 2019, Pacific Directors of Clinical Services Meeting. A recommendation from the Pacific Directors of Health was then passed on to: (iii) the Pacific Heads of Health Meeting April 4-5, 2019, also attended by team members. Findings were again presented by the team to the Pacific Update 
conference sponsored by the Australia National University and the Fiji National University in Suva, 3 July 2019.

\section{Results}

Information gathered through our questionnaire and interviews addressed, in general, three critical issues in the provision of OMR services: the level and cost of service delivery (which had not previously been summarised), the status and implementation of OMR policy in the selected PIC (which was variable and inconsistent), and population access to OMR services (which had not been assessed using available data).

Service delivery and spending

Routine data collection across the PIC is patchy and often incomplete in recording OMR utilization and financing. Full, accurate data are not available. According to the information collected in our survey, there were 2639 OMR cases across all 16 PIC in 2017, three-quarters of which were from PIC associated with a high-income country (such as France or the USA). For the remaining PIC (as illustrated in Figure 1), those with smaller populations appear to be relatively more dependent on OMR for access to SCS. Smaller nations such as Palau, Cook Islands, Nauru, Tuvalu, Niue or Tokelau had relatively higher levels of OMR per 1000 population than the larger nations (like Fiji, Solomon Islands or Samoa). 
Figure 1. Population and OMR rate per 1000 in 15 selected PIC, 2017

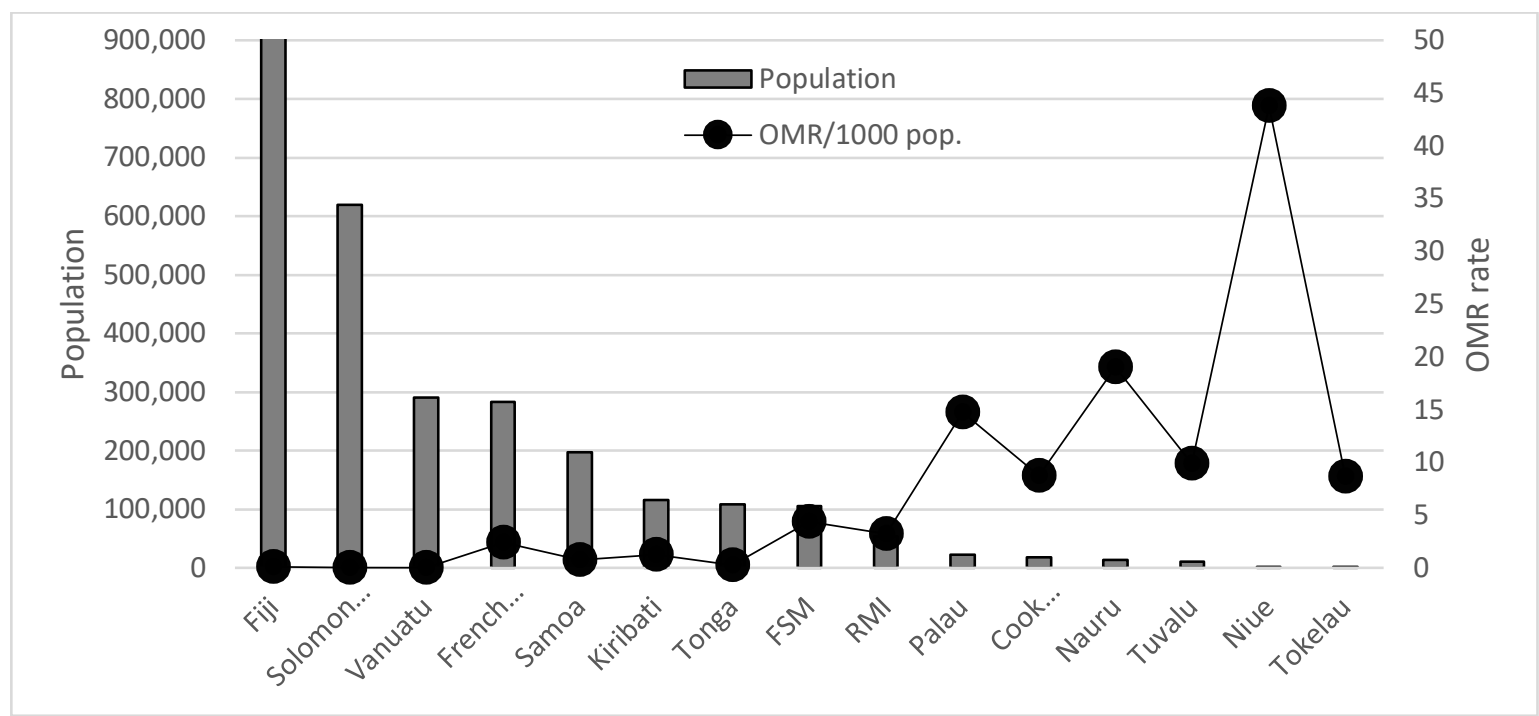

Source: WHO and the authors (Nossal Institute et al., 2019).

Across all 16 PIC, routine data on government OMR expenditures was inconsistent and incomplete. Information gathered in our survey suggested total OMR spending by PIC governments was relatively stable during 2013-2017 (though this varied between countries). Spending was largely concentrated in New Caledonia, French Polynesia and the Federated States of Micronesia's MiCare scheme (which accounted for USD 95 million out of a total USD 125 million across the 16 PIC in 2017). However, in the smaller independent PIC, expenditures increased. The results of our survey suggest that total government-related spending on OMR may have risen by a third during 2013-2017 across the eight smaller independent PIC. As illustrated in Figure 2, spending in Palau, Nauru, Tuvalu and Kiribati increased significantly. Spending in Samoa fell. 
Figure 2: Total OMR spending in 11 selected PIC, 2013-2017

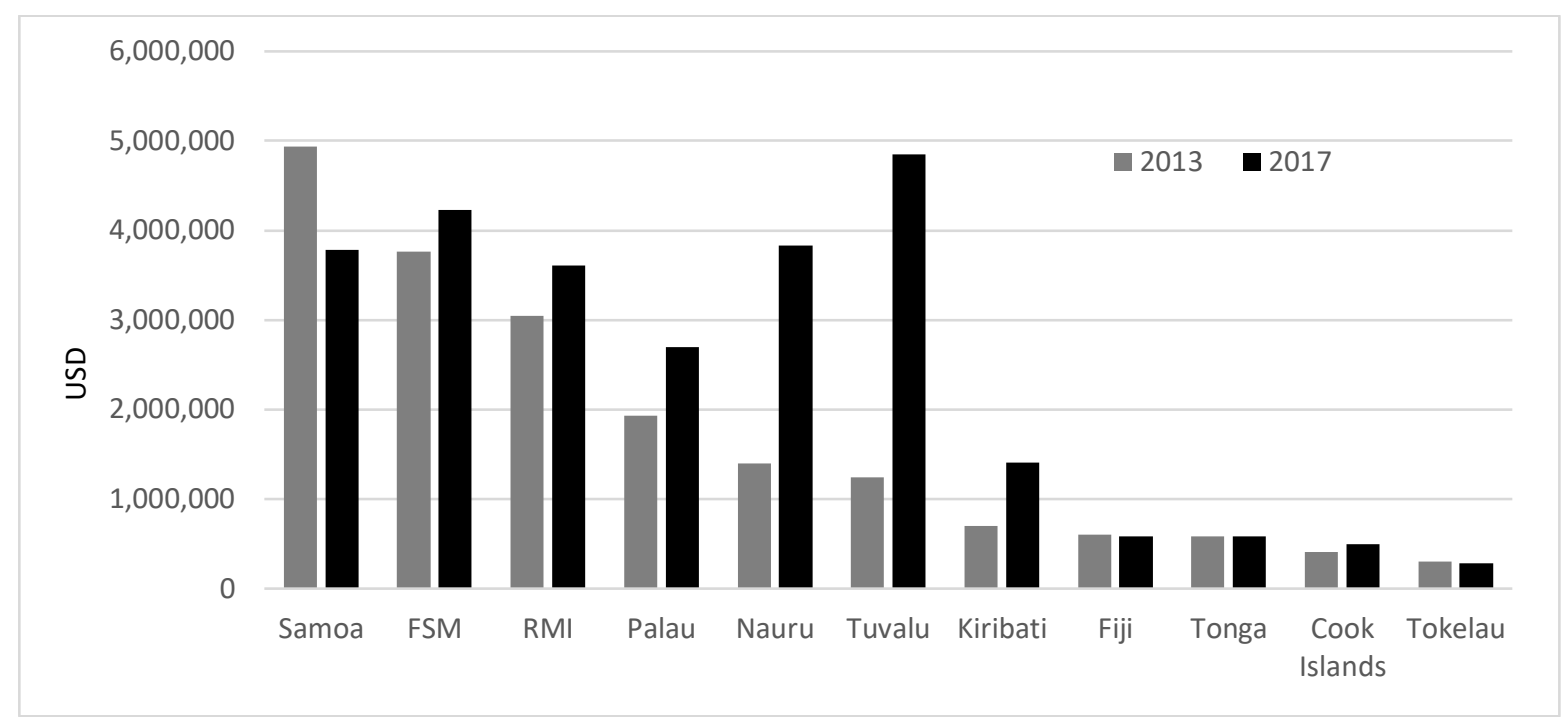

Source: The authors, based on interview data and WHO (2019):

Mapping of OMR and VSMT in Pacific Island Countries-A Pathway for Regional Cooperation Towards UHC, Division of Pacific Technical Support, Suva.

In addition to government financing, out-of-pocket expenditures for OMR are also common, particularly for medications, diagnostic tests, transport, accommodation, and food. These charges may occur even where PIC health services are heavily subsidised or provided free of charge.

The historic pattern of referral - principally to Australia, New Zealand, and Hawaii - has changed in recent years as various PIC look for lowercost alternatives in China, India, Malaysia, the Philippines, Singapore and Taiwan. These referral patterns are illustrated in Figure 3. The lack of available information means assessing the efficiency and effectiveness of OMR service providers is a significant challenge for PIC governments. 


\section{Figure 3. Pattern of referral from PIC to OMR provider countries}

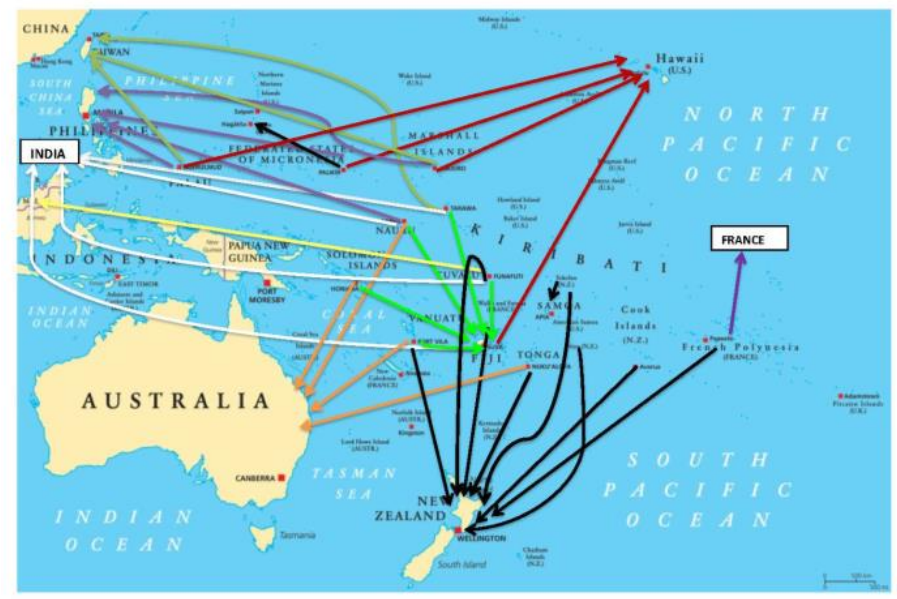

Source: WHO and the authors (Nossal Institute et al., 2019)

\section{OMR policies and systems}

Most, but not all, PIC had some form of written OMR policy, though not all made the policy available to the public. Across the 16 PIC studied, nine had written policies and made them publicly available, three had policies that were not publicly available, and four had no policy.

Most PIC support, to some extent, government-funded OMR schemes, often co-funded through agreements with donors (bilateral and charitable organizations). Across the spectrum of administrative arrangements, two broad groups emerged: those PIC whose health systems (and OMR processes) operate within the context of a larger high-income country health or health insurance system (particularly with France and the United States, and to some extent New Zealand); those who operate independently, supported variously by donor partners and charitable organizations. ${ }^{3}$

Inclusion and exclusion criteria for OMR patient selection vary by country. In many cases, patient referral for OMR was made on a case-bycase basis at the discretion of the OMR Committee or Health Minister. Some countries set a limit on the number of referrals per person while other countries set a limit on annual cost per patient. Exclusions under OMR policy also varied but in general covered:

- Patients with NCDs (in some countries);

- Patients above a maximum eligible age;

- Patients with co-morbidities;

- Patients not enrolled in the national insurance scheme (Federated States of Micronesia);

- Patients with private health insurance (although not in all countries);

\footnotetext{
${ }^{3}$ See Table 2 below for further details.
} 
- Patients with ability to pay for some services or to fund airfares or support costs.

Access to services

Few PIC had well-established health information management systems for OMR. Where available, the records included only those patients sent overseas through a government scheme, though it is known that many more access overseas services either alongside official systems or privately. As the OMR patient numbers, where available, included only those sent overseas for care and not all those who may have applied for the scheme, it was impossible to assess access or unmet need (demand and distribution at population level). Moreover, OMR schemes are generally not publicised, applications are often triggered by specialist assessment, and many patients use private insurance or company funded schemes.

Even so, it appears that OMR patient numbers are by far the greatest in those PIC associated with larger high-income countries (particularly France and the USA), where our research shows the annual OMR rate was 3.83 per 1000 population in 2017 (highest in Niue 44.75 and Palau 14.73) compared to 0.34 for the independent PIC (highest in Nauru 19.05 and Tuvalu 9.91).

\section{Discussion}

The findings from this scoping study raise a few questions about the provision of OMR services through PIC health systems. The rising demand for, and rising cost of, OMR services are challenges that particularly confront those independent Island states not associated with high-income countries like the USA, France or New Zealand. Reforms to OMR policies, management and provision are urgently needed in these countries, which can be summarised under the following sub-headings.

\section{Utilization of services}

The highest rates of OMR service provision per 1000 population are - with the exception of Nauru and Tuvalu - in PIC associated with the USA, France and New Zealand. For these, OMR services and funding form one part of the health-system support provided through the high-income country.

The two smallest independent PIC (Nauru and Tuvalu) understandably have among the highest rates of OMR in the region, while the remaining six (Kiribati, Samoa, Solomon Islands, Tonga, Fiji, Vanuatu) appear to be relatively under-serviced - implying there is extensive unmet need for OMR in these countries.

These eight independent PIC rely predominantly on domestic funding (in many cases supported by donor agencies) for the provision of OMR services. These differences between the independent PIC and those associated with high-income countries provide additional challenges in working towards regional cooperation in accessing OMR care. Particular attention is needed, therefore, to strengthening the management, funding, and monitoring of OMR services in these independent PIC. 


\section{OMR providers}

While it appears that the costs of accessing new OMR providers are lower in Philippines, India and elsewhere - compared to traditional providers in the USA, Australia or New Zealand - it is not yet clear that treating OMR patients in India (for example) represents better value for money compared to New Zealand (see World Bank, 2018).

Routine information on service providers and outcomes is not collected across most PIC, making it difficult for health advisors to manage the selection or the monitoring of providers or to determine the costeffectiveness of provider activities. Significantly, there has so far been no formal assessment or evaluation of the quality of care or health outcomes of OMR service providers.

Moreover, there appears to be an imbalance in negotiating power between PIC and OMR service providers. Each PIC negotiates the terms and conditions of contracts for OMR service provision, though they are usually in a weak bargaining position due to the small number of OMR patients according to each sub-speciality.

\section{OMR implementation}

A key limitation, currently, is the absence of regular review of OMR policy and practice. Generally, very little data is available to policy makers to assess and monitor OMR schemes or to assess need for budgetary adjustment and re-allocation. Because few PIC have well-established and well-maintained data systems for recording VSMT, OMR and SCS access, expenditures and outcomes, there is in most cases no formal system for tracking the referral process or patient outcomes. The exceptions are the states and territories that provide access to OMR together with an associated high-income country.

Improving OMR delivery will be difficult to achieve, however, as long as OMR is treated as a parallel activity to the national health system (whether by default or by design) and lacks the necessary level of integrated planning, management and monitoring.

\section{Policy reforms}

For the independent PIC especially, potentially managing OMR as the final step in an organised process moving through the primary-to-tertiary care spectrum in a two-way referral process provides the best opportunity for improved care. PIC health systems are predominantly governmentfunded, with strong donor support, which provides a firm foundation for managing OMR within the wider national health-referral system. It is known that public subsidization of costs related to medical travel and treatment overseas is common in other small island states, such as the Maldives and the Caribbean countries (Suzana, Walls, Smith, \& Hanefeld, 2018). Similar challenges among the Caribbean countries have led to a process of collaboration and regionalization in the delivery of SCS - and access to OMR - with lessons for the Pacific region (WHO, 2019; Preston et al., 2016). 
In a well-functioning referral system, an organized triage process that offers the most appropriate care at the time necessary is the basis for effective patient pathways, more consistent management, and more efficient service delivery. At the level of domestic service delivery, experienced PIC clinical staff have the capacity to determine what can be treated locally; further clinical skill may be provided by VSMT clinicians, followed by referral to OMR where necessary.

Within this health-system framework, a number of essential reforms become possible:

- Harmonization of VSMT and OMR activities within Ministries of Health.

- Consistent recording of OMR services within the national health management information system.

- Monitoring the implementation of OMR services to reinforce national decision making.

- Development of common reporting templates among PIC, based on a format consistent with the WHO International Classification of Diseases.

- Collecting consistent patient records as one part of the unified national referral system.

- Monitoring providers using consistently collected information on patient outcomes.

- Maintaining a known list of preferred providers - together with consistent provider-payment mechanisms - to create an incentive for meeting the required standards.

- Implementation of provider performance standards could set through a form of agreement or contract negotiation with providers.

- Registration or (eventually) accreditation of OMR providers enabling a more strategic approach (nationally and regionally) to purchasing OMR services.

- Strengthening cooperation across the region, including further investigation of strategic purchasing procedures.

\section{Planning and prioritisation}

Managing OMR in this way allows the process of resource allocation to be dealt with routinely as one part of the overall health systems strategy, alongside primary care, hospital services and VSMT. Decision making in the provision of OMR and other SCS services can then be based on rigorous planning and prioritization processes within the country context, according to accepted prioritization principles (Chalkidow et al., 2016; Terwindt, Rajan \& Soucat, 2016).

Ultimately, decisions need to be made about resource allocation and the most efficient way to deliver specialised clinical services equitably, and what sort of priority to give to OMR. This will eventually require some form of cost-benefit or cost-effective analysis that compares the three SCS alternatives: local capacity, VSMT and OMR. The first step in this process is to produce consistent, routine data in an organised referral system that incorporates these three approaches. 
Key questions of resource allocation that emerged in our study could then be addressed:

- Managing demand (unmet need and equitable access): uniform application of the 'good prognosis' patient selection criterion used by most PIC (defined as a five-year survival rate of more than $50 \%$ ); implementing consistent inclusion and exclusion criteria across all PIC.

- Cost control: for example, applying an annual budget ceiling for provision of OMR services, equitable application of limits on eligibility, a ceiling on annual OMR visits or costs per person, means testing for co-payments based on capacity to pay.

- Purchasing of services: including regional or national accreditation systems for OMR service providers, uniform standards for any agreement negotiated with OMR service providers, provider payment mechanisms with, for example, performance-based incentives, or collective purchasing arrangements.

In the longer term, PIC governments could then be in a position to collaborate across the region through a preferred provider network of accredited OMR facilities in recipient countries with guidelines as to price setting and clinical performance. The Pacific Register of Qualifications and Standards (SPC, 2011), for which the SPC has oversight, could provide a framework for such further harmonization across the region in a way that draws lessons from the experience in other small-island regions, such as the Eastern Caribbean Network of Care for Specialized Clinical Services.

\section{Conclusion}

Meeting in Fiji in April 2019, PIC heads of health, heads of clinical services, and health ministers all considered measures to strengthen OMR delivery. ${ }^{4}$ These policy makers recommended strengthening clinical decision making, harmonization within and between countries, stronger data management and analysis, and more attention to the quality of care delivered by OMR providers. These measures can be classified as: (i) improving the health system referral process; and (ii) strengthening service delivery.

Policy reform is a governance process, and the challenges are greatest in those PIC not in association with a larger high-income country. While all PIC are committed to ensuring equitable access to health services, the challenge of providing more effective, efficient and equitable OMR services can be met only through a consistent step-by-step process of integrating OMR into the national health referral system, with equity of access. Looking towards the future, such a process offers the potential to reduce costs through strategic purchasing of services supported by agreement between PIC to share resources and provide OMR within the region.

\footnotetext{
${ }^{4}$ Recommendations from the 9th Directors of Clinical Service meeting held in Denarau, Fiji 1-2 April 2019, and the Pacific Heads of Health Meeting, 3-5 April 2019, and endorsed by the Pacific Ministers of Health
} 


\section{Acknowledgements}

The study on which this article is based was carried out for the Asia Pacific Observatory on Health Systems and Policies as a collaboration between the Nossal Institute, the World Health Organization Western Pacific Regional Office-Pacific Division of Technical Support, the WHO Pacific Office and the SPC. The authors wish to thank the Ministry of Health officials in various Pacific Island Countries, including the Permanent Secretaries and Pacific Health Ministers, who contributed their time and shared information. Funding for this work was provided by the Asia Pacific Observatory on Health Systems and Policies. 


\section{References}

Biscoe G, Fakakovikaetau T, Condon R \& Monteiro S. (2015). Medical Workforce Support Program (Vanuatu)-Investment design (revised and updated). Department of Foreign Affairs and Trade. https://www.dfat.gov.au/sites/default/files/medical-workforcesupport-program-vanuatu-design-document.pdf

Blick G \& Smith J. (2015). Evaluation of the New Zealand Medical Treatment Scheme. New Zealand Ministry of Foreign Affairs and Trade. https:/ / www.mfat.govt.nz/assets / Aid-Prog-docs / AidEvaluation-NZ-medical-treatment-scheme-130315.pdf

Boudville A, Irava W, Motofaga S, Gilbert K \& Annear PL. (2020). Overseas Medical Referral: the health system challenges for Pacific Island Countries. Policy Brief, Asia Pacific Observatory on Health Systems and Policies, World Health Organization.

Chalkidou K, Glassman A, Marten R, Vega J, Teerawattananon Y, Tritasavit N, et al. (2016). Priority-setting for achieving universal health coverage. Bull World Health Organ, 94(6):462-7.

Hawley NL \& McGarvey ST. (2015). Obesity and diabetes in Pacific Islanders: the current burden and the need for urgent action. $J$ Current Diabetes Reports, 15(5):29.

Hoy D, Roth A, Viney K, Souares Y \& Lopez AD. (2014). Findings and implications of the Global Burden of Disease 2010 Study for the Pacific Islands. Preventing Chronic Disease, 11:E75-E.

Irava W, Mahalakanda S \& Prasad R. (2014). A situational analysis and assessment of the overseas patient referrals systems in four Pacific Islands countries. Australian Department of Foreign Affairs and Trade.

Irava W. (2011). Comparing the cost of cardiac treatment between Government, private insurance, and cardiac visiting teams. Fiji: Strengthening Specilized Services in the Pacific Program. Australian Department of Foreign Affairs and Trade.

Kushner AL, Cherian MN, Noel L, Spiegel DA, Groth S \& Etienne C. (2010). Addressing the Millennium Development Goals from a surgical perspective: essential surgery and anesthesia in eight lowand-middle-income countries. Archives of Surgery (Chicago, Ill : 1960), 145(2):154-9.

Mannava P, Abdullah A, James C, Dodd R \& Annear PL. (2015). Health systems and noncommunicable diseases in the Asia-Pacific region: a review of the published literature. Asia Pacific Journal of Public Health, 27(2):NP1-NP19.

Masterton JP, Moss D, Korin SJ \& Watters DAK. (2014). Evaluation of the medium-term outcomes and impact of the Rowan Nicks Scholarship Programme. ANZ Journal of Surgery, 84(3):110-6.

Natuzzi ES \& Kushner A, Jagilly R, Pickacha D, Agiomea K, Hou L, et al. (2011). Surgical care in the Solomon Islands: A road map for 
universal surgical care delivery. World Journal of Surgery, 35(6):1183-93.

Negin J. (2011). Sector-Wide Approaches for health: a comparative study of experiences in Samoa and the Solomon Islands. Health Policy and Health Finance Knowledge Hub Working Paper Series. Nossal Institute for Global Health, 2010. See: Global Public Health, 7(2):137-48. Doi 10.1080/17441692.2011.584326

Nossal Institute, SPC, \& World Health Organization. (2019). Mapping of OMRS and VSMT in Pacific Island Countries-A pathway for regional cooperation towards UHC. World Health Organization Division of Pacific Technical Support.

https://spccfpstore1.blob.core.windows.net/digitallibrarydocs / files / b8/b85e07d59a1 fa3fec9e8125d6bb3eb2a.pdf?sv=2015$12-$

$11 \&$ sr=b\&sig=M1VRnqYoVgWIdUvEziEnNVSzgKIcKLeqYPqpFPZ48\%2 $\mathrm{BI} \% 3 \mathrm{D} \& \mathrm{se}=2020-10$

$27 \mathrm{~T} 05 \% 3 \mathrm{~A} 40 \% 3 \mathrm{~A} 01 \mathrm{Z} \& \mathrm{sp}=\mathrm{r} \& \mathrm{rscc}=\mathrm{public} \% 2 \mathrm{C} \% 20 \mathrm{max}-$ age $\% 3 \mathrm{D} 864000 \% 2 \mathrm{C} \% 20 \mathrm{max}-$

stale\%3D86400\&rsct=application\%2Fpdf\&rscd=inline\%3B\%20filena me\%3D\%22IP_6_Item4_Technical_Report_Mapping_of_OMRS_and_V SMT.pdf\%22

Plowman B. (2015). Independent evaluation of the Tertiary Health Pacific Islands Program and strengthening Specialised Clinical Services in the Pacific. Department of Foreign Affairs and Trade.

Preston C, Chahal HS, Porras A, Cargill L, Hinds M, Olowokure B, et al. (2016). Regionalization as an approach to regulatory systems strengthening: a case study in CARICOM member states. Revista panamericana de salud publica, 39(5):262-8.

SPC. (2011). Pacific Register of Qualifications and Standards. [Available from: http://prqs.spc.int/]

Suzana M, Walls H, Smith R \& Hanefeld J. (2018). Achieving universal health coverage in small island states: could importing health services provide a solution? BMJ Global Health, 3(1):e000612. doi:10.1136/bmjgh-2017-000612

Terwindt F, Rajan D \& Soucat A. (2016). Chapter 4. Priority setting for national health policies, strategies and plans. In: Schmets G, Rajan D, Kadandale S, es. Strategizing national health in the 21st century: a handbook. World Health Organization.

Theile DE \& Bennett RC. (1998). The Pacific Islands Project: the first three years. ANZ Journal of Surgery, 68(11):792-8.

World Bank. (2018). Vanuatu - health financing system assessment: spend better. World Bank Group.

(http://documents.worldbank.org/curated/en/39385152881316811 4/Vanuatu-Health-financing-system-assessment-spend-better, accessed 16 March 2020).

World Bank. (2014). Non-Communicable Disease Roadmap Report. World Bank Group. 
http://documents.worldbank.org/curated/en/53455146833238759 9/pdf/893050WPOP13040PUBLIC00NCDORoadmap.pdf

World Health Organization, Ministry of Health and Medical Services, \& SPC. (2015). Yanuca Island Declaration on health in Pacific island countries and territories. Eleventh Pacific Health Ministers Meeting, 15-17 April 2015, Yanuca, Fiji. World Health Organization. https:/ /apps.who.int/iris/handle/10665/208257

World Health Organization. (2017). Sixty-Eighth Session of the Regional Committee for the Western Pacific, Summary Report-Side-Meeting on Responding to the Need for Specialized Tertiary Care in Small Island States. World Health Organization.

(https://www.who.int/westernpacific/about/governance/regionalcommittee/session-68).

World Health Organization. (2019) Pacific Islands Meeting on Subregional Collaboration for Specialized Healthcare Services, February 26. World Health Organization Western Pacific Regional Office. https:/ / iris.wpro.who.int/bitstream/handle/10665.1/14377/RS2019-GE-09-FJI-eng.pdf

World Health Organization \& World Bank. (2017). Healthy systems for universal health coverage-a joint vision for healthy lives. World Health Organization, The World Bank.

https://www.uhc2030.org/fileadmin/uploads/uhc2030/Documents /About_UHC2030/mgt_arrangemts_docs/UHC2030_Official_docu ments/UHC2030_vision_paper_WEB2.pdf

Yamamoto TS, Sunguya BF, Shiao LW, Amiya RM, Saw YM \& Jimba M. (2012). Migration of health workers in the Pacific Islands: a bottleneck to health development. Asia-Pacific journal of Public Health, 24(4):697-709. 
Table 1. Response to questionnaires and other data collection

\begin{tabular}{|c|c|c|c|}
\hline & $\begin{array}{c}\text { Countries included in } \\
\text { analysis } \\
\text { (according to WHO definition of Pacific } \\
\text { Island Countries) * }\end{array}$ & $\begin{array}{c}\text { Questionnaires } \\
\text { completed? }\end{array}$ & $\begin{array}{c}\text { Documents } \\
\text { analysed? }\end{array}$ \\
\hline 1 & Cook Islands & $\mathrm{Y}$ & $\mathrm{Y}$ \\
\hline 2 & Federated States of Micronesia & $\mathrm{Y}$ & $\mathrm{Y}$ \\
\hline 3 & Fiji & $\begin{array}{l}\mathrm{N} \text { (secondary data } \\
\text { only) }\end{array}$ & $\mathrm{Y}$ \\
\hline 4 & French Polynesia & $\mathrm{Y}$ & $\mathrm{Y}$ \\
\hline 5 & Kiribati & $\mathrm{Y}$ & $\mathrm{Y}$ \\
\hline 6 & Nauru & $\begin{array}{l}\mathrm{N} \text { (secondary data } \\
\text { only) }\end{array}$ & $\mathrm{Y}$ \\
\hline 7 & New Caledonia & $\begin{array}{l}\mathrm{N} \text { (secondary data } \\
\text { only) }\end{array}$ & $\mathrm{Y}$ \\
\hline 8 & Niue & $\mathrm{Y}$ & $\mathrm{Y}$ \\
\hline 9 & Palau & Y (by remote contact) & $\mathrm{Y}$ \\
\hline 10 & Republic of Marshall Islands & $\mathrm{Y}$ & $\mathrm{Y}$ \\
\hline 11 & Samoa & Y (by remote contact) & $\mathrm{Y}$ \\
\hline 12 & Solomon Islands & $\mathrm{Y}$ & $\mathrm{Y}$ \\
\hline 13 & Tokelau & $\mathrm{Y}$ & $\mathrm{Y}$ \\
\hline 14 & Tonga & $\mathrm{Y}$ & $\mathrm{Y}$ \\
\hline 15 & Tuvalu & $\mathrm{Y}$ & $\mathrm{Y}$ \\
\hline \multirow[t]{2}{*}{16} & Vanuatu & $\mathrm{Y}$ & $\mathrm{Y}$ \\
\hline & Additional interviews & & \\
\hline .. & Australia & Telephone interview & n.a. \\
\hline \multirow[t]{2}{*}{.. } & New Zealand & Telephone interview & n.a. \\
\hline & Countries not included & & \\
\hline .. & American Samoa & $\mathrm{N}$ & $\mathrm{N}$ \\
\hline .. & Guam & $\mathrm{N}$ & $\mathrm{N}$ \\
\hline .. & Northern Mariana Islands & $\mathrm{N}$ & $\mathrm{N}$ \\
\hline .. & Papua New Guinea & $\mathrm{N}$ & $\mathrm{N}$ \\
\hline .. & Wallis and Futuna Islands & $\mathrm{N}$ (no response) & $\mathrm{N}$ \\
\hline
\end{tabular}

* See http://www.who.int/countryfocus WHO/CCO/13.01/southpacific 
Table 2. Classification of OMR arrangements by type of scheme

\begin{tabular}{|l|l|}
\hline \multicolumn{2}{|l|}{ Supported by health financing in associated high-income country } \\
\hline French territories & New Caledonia, French Polynesia \\
\hline USA Compact Agreements & $\begin{array}{l}\text { Federated States of Micronesia, Palau, } \\
\text { Republic of the Marshal Islands }\end{array}$ \\
\hline NZ free association & Niue, Cook Islands, Tokelau \\
\hline $\begin{array}{l}\text { PIC government- and donor-supported schemes } \\
\text { (major bilateral and charitable organizations) }\end{array}$ \\
\hline Government-funded & Fiji, Kiribati, Samoa \\
\hline $\begin{array}{l}\text { +New Zealand Medical Treatment } \\
\text { Scheme }\end{array}$ & Fiji, Tonga, Tuvalu, Vanuatu \\
\hline +Australian bi-lateral aid, and PNG & Nauru \\
\hline +Taiwan Health Care Fund & $\begin{array}{l}\text { Kiribati, Nauru, Solomon Islands [Palau, } \\
\text { RMI] }\end{array}$ \\
\hline $\begin{array}{l}\text { +NSW government/St Vincent's Private } \\
\text { Hosp. }\end{array}$ & Solomon Islands \\
\hline
\end{tabular}

